\title{
Diagnosis and Identification for the Variation of the Flood Series based on Hydrological Variation Diagnosis System
}

\author{
Binbin Li \\ State Key Laboratory of Water Resources and \\ Hydropower Engineering Science \\ Wuhan University \\ Wuhan, China \\ e-mail: reben_1987@163.com
}

\author{
Ping Xie \\ State Key Laboratory of Water Resources and \\ Hydropower Engineering Science \\ Wuhan University \\ Wuhan, China \\ e-mail: 415507332@qq.com
}

\begin{abstract}
In this study, we used hydrological alteration diagnosis system to acquire the flood variation form and degree of Xuanen County under changing environments, and analyzed its cause mechanisms using the formula of Chézy-manning. The results showed that: firstly, the annual maximum daily flow series from 1962-2013 jumped a downward moderate variation in 1999, which indicated that the dual influence of human activities leaded to the variation of the annual maximum daily flow. Secondly, river canalization has started in 2005 and completed in 2012, which has reduced the flood discharge at equal water level, aggravating the flood variation to a certain extent. Finaly, human activities have great influence on the flood control abilities of urban water bodies of Xuanen. Xuanen County river canalization resulted in decrease of the flood flow, exacerbating the variation of flood, thereby the flood warning plan needed to adapt to the changing environment, which would make river flood prevention decision more scientific and feasible.
\end{abstract}

Keywords- Hydrological Variation Diagnosis System; Hurst Coefficient; Flood Variation; Changing Environments; Xuanen County

\section{INTRODUCTION}

As one of the major natural disasters endangering human social and economic development, and ecological environment, flood since ancient times. Therefore, flood control is always a significant issue which is related to people's safety and the prosperity and decline of the nation through the ages. In order to resist against flood, reservoirs and other hydraulic engineering projects have come into being, so that the basin surface conditions changed. Due to the influence of climate change and human activities, the formation and variation in regularity are changed and the consistency of flood series is destroyed, affecting the frequency and intensity of floods [1].

Xuanen County in Hubei province is located in a large flat valley bordering on both sides of the Zhongjian River whose upstream has Tongziying medium reservoir and Longdong medium reservoir, which plays a role in regulation for the flood upstream. Its downstream has Dongping large reservoir, whose backwater has a certain influence to midstream and downstream of the river. In recent years, Xuanen County suffered heavy rains attacks and frequent flood disasters. Therefore, channel improvement project of Xuanen County started in 2005, left bank project completed in 2009, and both sides of the river bank completed in 2012. After years of treatment, natural river course of Zhongjian River district section has been transformed into nearly parallel and regular on both sides, and the trend of the river remain unchanged before and after the river canalization.

There are many different methods to diagnose the hydrological variation, the methods that used to diagnose the jump variation such as Sequential Cluster, Rank-Sum Test, Sliding $\mathrm{T}$ Test etc. and the Spearman Rank Correlation Test, Kendall Rank Correlation Test etc. used to diagnose the trend variation [2-4]. Use of one or two statistical tests for time series analysis is quite common for easy decision making [5-8]. However, the variation form is complex, and the classification of variation degree is not considered in the hydrological series with variation. Machiwal and Jha recommended that an adequate number of statistical tests must be applied for detecting a particular time series characteristic and the results should be analyzed critically to arrive at a reliable decision [9-10]. In order to improve the methods above, Xie put forward Hydrological Variation Diagnosis System (HVDS) [11].

In order to better reveal flood variation regularity of Xuanen County from statistical meaning and physical meaning, by combining the hydrological variation diagnosis system with the measured hydrological series, and the variation form and the degree of the flood series was calculated. Lastly its cause analysis was conducted using the formula of Chézy-manning. The results not only is beneficial for the local flood variation countermeasure and water resource utilization, but also has great reference value on water conservancy project construction and flood control and disaster mitigation planning of the Zhongjian River Basin.

\section{HYDROLOGICAL VARIATION DIAGNOSIS SYSTEM}

There are definite composition and stochastic composition contained in the hydrological series, and the definite composition could be decomposed as circle, 
tendency and jump elements. The hydrological series is stationary if the circle, tendency and jump elements have nothing to do with it, which means the physical causes have no change as time goes on. The statistical regulations, such as the distribution style and parameters $(C v, C s$ etc.), are consistent with no alteration in the time scale of the hydrological series and the hydrological data fluctuates in random based on the mean value. Otherwise, the hydrological series is non-stationary and statistical regulations are inconsistent, the physical causes and hydrological parameters were changed in the time scale of the hydrological series. Therefore, the definition of hydrological alteration in the statistical scale is the distribution style and parameters are changed obviously within the hydrological series.

Hydrological Variation Diagnosis System could diagnose the trend and jump alteration, and it is composed of three parts, i.e. preliminary diagnose, detailed diagnose and comprehensive diagnose.

The method of Hydrograph Analysis, Sliding Average Analysis and Hurst Coefficient Analysis are used to diagnose whether the hydrological variation exist or not in the process of preliminary diagnose, and based on the relationship between Hurst coefficient and the parameter of Fractional Brownian Motion to classify the degree of hydrological variation, the principles of diagnosis and classification as follows.

The long-term relativity characteristics of temporal series could be described by the Hurst coefficient $h$. If $h=0.5$, the temporal series is random and the variation tendency is not impacted by now; if $h$ is approaching to 1.0 , it means the variation tendency of future is same to now and the durative of temporal series is positive; if $h$ is approaching to 0.0 , the situation is reverse. The stochastic feature of temporal series is disturbed by the long-term relativity and the alteration happens, and the farther the $h$ deviated from 0.5, the more apparent the alteration is. Therefore, based on the Hurst coefficient $h$, the stochastic feature and alteration of temporal series could be diagnosed, and with the observation temporal series, the $h$ could be calculated by the Rescaled Range Analysis method as follows [12]:

$$
R / S=(c \tau)^{h}
$$

Fractional Brownian motion [13] was born with the combination of random process and fractal theory and it was put forward by Mandelbrot from the ordinary Brownian motion. The long-term relativity could be described by the motion parameter $H$, the relationship between $\mathrm{H}$ and correlation function $C(t)$ as follows [14]:

$$
C(t)=-\frac{E\left[B_{H}(-t) B_{H}(t)\right]}{E\left[B_{H}(t)\right]^{2}}=2^{2 H-1}-1
$$

The motion parameter $H$ is equivalent to Hurst coefficient $h$ in logic and definition, so the correlation function $C(t)$ of temporal series could be calculated with the $h$ already known. The hypothesis testing of $C(t)$ could be carried out under a certain confidence degree $\alpha$ : if $C(t)$ is smaller than the critical value $r_{\alpha}$, the long-term relativity is not significant and there is no variation happens in the temporal series; else the long-term relativity is significant and the alteration exists. There is a situation existing in the application of $C(t)$, even if the hypothesis testing passed the testing with the confidence degree $\alpha$, it may not passed the testing with the confidence degree $\beta(\alpha>\beta)$, that means $r_{\alpha}<C(t)<r_{\beta}$. In this situation, the variation is significant with the confidence degree $\alpha$ and not significant with the confidence degree $\beta$, it is named weak variation. If $C(t)$ is more than and equal to $r_{\beta}$, the variation is obvious and the classification could be considered based on the correlation degree, as Table 1 shows below.

TABLE I. ClasSIFICATION OF VARIATION DEGREE.

\begin{tabular}{ccc}
\hline$C(t)$ & $h$ & variation degree \\
\hline $0 \leqslant C(t)<r_{\alpha}$ & $0.5 \leqslant h<h_{\alpha}$ & none \\
$r_{\alpha} \leqslant C(t)<r_{\beta}$ & $h_{\alpha} \leqslant h<h_{\beta}$ & weak \\
$r_{\beta} \leqslant C(t)<0.6$ & $h_{\beta} \leqslant h<0.839$ & moderate \\
$0.6 \leqslant C(t)<0.8$ & $0.839 \leqslant h<0.924$ & strong \\
$0.8 \leqslant C(t) \leqslant 1.0$ & $0.924 \leqslant h \leqslant 1.0$ & huge \\
\hline Note: $h_{\alpha}=\frac{1}{2}\left[1+\ln \left(1+r_{\alpha}\right) / \ln 2\right], \alpha>\beta$ &
\end{tabular}

If there is no variation in the series by the result of preliminary diagnose, the analysis and investigation of causes should be carried out to confirm the result; else the process of detailed diagnose will be activated.

In the process of detailed diagnose, in order to detect the trend variation, the methods of Linear Correlation Coefficient, Spearman Rank Correlation Test and Kendall Rank Correlation Test are used. In order to detect the jump variation, the methods of Sequential Cluster, LeeHeghinian, Rank-Sum Test, Sliding F Test, Sliding T Test, Runs Test, R/S Analysis, Brown-Forsythe, Mann-Kendall and Bayesian are used. After the trend and jump diagnose, the process of comprehensive diagnose will be activated.

In the process of comprehensive diagnose, the comprehensive results of trend diagnose and jump diagnose will be achieved based on the results of detailed diagnose. The fitting degree of hydrological series and the proportion of trend or jump will be estimated by the coefficient of efficiency, and the bigger one will be accepted as the result of hydrological variation. With the investigation and analysis of the actual conditions, the conclusion and the style of alteration will be confirmed at last.

Compared with the traditional simplex alteration diagnosis methods, HVDS could diagnose the alteration comprehensively and considered the variation degree classification in the hydrological series, it is comprehensive in the indexes and the alteration analysis result is credible. Therefore, the HVDS was used to diagnose the hydrological variation in this paper.

\section{DIAGNOSIS FOR THE VARIATION OF THE FLOOD SERIES BASED ON HVDS}

Under the condition of the first degree of confidence $\alpha=0.05$ and the second degree of confidence $\beta=0.01$, the HADS was used to analyze the alteration of the average annual maximum monthly rainfall series from 1956-2010 (the calculation for the arithmetic mean of the average annual maximum monthly rainfall at Xianfeng, Xiaoguan, Xuanen, Longping, Xicaoba and Tongziying station) and 
the annual maximum daily flow series of Xuanen station from 1962-2013.

The result of preliminary diagnose for the annual maximum daily flow series of Xuanen station showed that moderate alteration existed from the results of Table 2: the Hurst coefficient $h=0.749$, the first Hurst coefficient confidence limit $h_{\alpha}=0.676$ and the second Hurst coefficient confidence limit $h_{\beta}=0.720, h>h_{\beta}$, which did not meet the consistent demand.

TABLE II. THE ALTERATION DIAGNOSIS RESULTS

\begin{tabular}{|c|c|c|c|c|}
\hline \multicolumn{4}{|c|}{ Hydrological elements } & flow $\left(\mathrm{m}^{3} / \mathrm{s}\right)$ \\
\hline \multirow{2}{*}{\multicolumn{2}{|c|}{ Preliminary diagnose }} & \multirow{2}{*}{\multicolumn{2}{|c|}{\begin{tabular}{|c|} 
Hurst coefficient \\
Ateration degree
\end{tabular}}} & 0.749 \\
\hline & & & & moderate \\
\hline \multirow{14}{*}{$\begin{array}{l}\text { Detailed } \\
\text { diagnose }\end{array}$} & \multirow{11}{*}{ Jump } & \multicolumn{2}{|c|}{ Sliding F } & $1999(+)$ \\
\hline & & \multicolumn{2}{|c|}{ Sliding T } & $1999(+)$ \\
\hline & & \multicolumn{2}{|c|}{ Lee-Heghinian } & $1999(0)$ \\
\hline & & \multicolumn{2}{|c|}{ Sequential Cluster } & 1999(0) \\
\hline & & \multicolumn{2}{|c|}{ R/S Analysis } & 1991(0) \\
\hline & & \multicolumn{2}{|c|}{ Brown-Forsvthe } & $1999(+)$ \\
\hline & & \multicolumn{2}{|c|}{ Runs Test } & $2004(+)$ \\
\hline & & \multicolumn{2}{|c|}{ Rank-Sum } & $1999(+)$ \\
\hline & & \multicolumn{2}{|c|}{ two degmentation } & $1968(0)$ \\
\hline & & \multicolumn{2}{|c|}{ Mann-kendall } & $1999(+)$ \\
\hline & & \multicolumn{2}{|c|}{ Bayesian analysis } & $1999(+)$ \\
\hline & \multirow{3}{*}{ Trend } & \multicolumn{2}{|c|}{ Linear Correlation } & + \\
\hline & & \multicolumn{2}{|c|}{ Spearman Rank } & + \\
\hline & & \multicolumn{2}{|c|}{ Kendall Rank } & + \\
\hline \multirow{6}{*}{$\begin{array}{c}\text { Comprehensive } \\
\text { diagnose }\end{array}$} & \multirow{3}{*}{ Jump } & \multicolumn{2}{|c|}{ Jump Point } & 1999 \\
\hline & & \multicolumn{2}{|c|}{ weight } & 0.78 \\
\hline & & \multicolumn{2}{|c|}{ significant } & $6(+)$ \\
\hline & Trend & \multicolumn{2}{|c|}{ significant } & $3(+)$ \\
\hline & \multirow{2}{*}{ Compare } & \multirow{2}{*}{$\begin{array}{c}\text { Efficiency } \\
(\%)\end{array}$} & Jump & 22.82 \\
\hline & & & Trend & 12.68 \\
\hline \multicolumn{4}{|c|}{ Diagnose Conclusion } & $1999(+) \downarrow$ \\
\hline
\end{tabular}

Detailed diagnose revealed that jump and tendency of the annual maximum daily flow series were both significant, then entered the process of comprehensive diagnose. The larger of the jump efficiency coefficient or the trend efficiency coefficient (jump efficiency coefficient $22.82 \%$ ) was selected as final variation form through jump comprehensive and trend comprehensive in the comprehensive diagnose. The final diagnose conclusion was the annual maximum daily flow series from 19622013 jumped a downward moderate variation in 1999, and its jump form was shown in Fig.1.

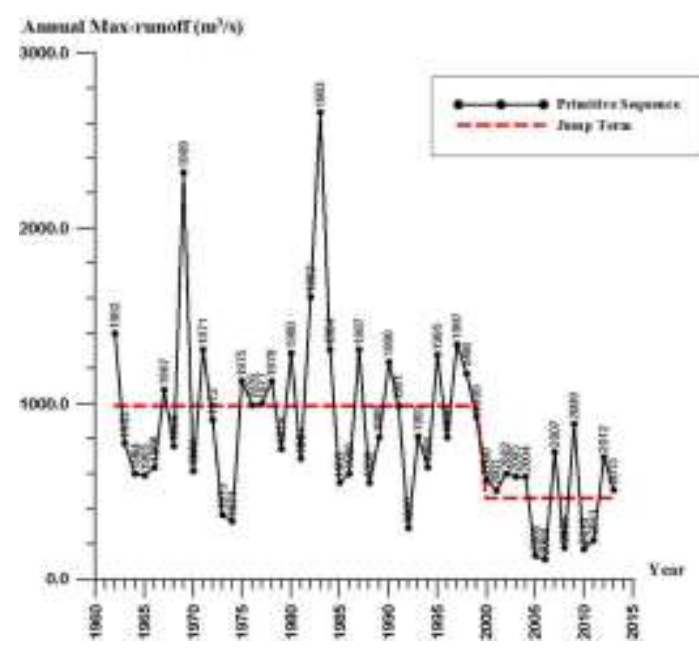

Figure 1. Jump alteration of annual max-runoff series at Xuanen station

River regulation and bank canalization have changed natural texture and shape of bank artificially, which causes the river hydraulic characteristics to change, and then causes the river course characteristics to change. The following will analyze the major factors affecting stagedischarge relation, such as the discharge section area and the roughness reflecting the size of resistance, and the variation situation of maximum flow series of Xuanen station was analyzed using the formula of Chézy-manning:

$$
Q=\frac{w R^{2 / 3} I^{1 / 2}}{n}
$$

Where $Q$ is volume of runoff, $w$ is the discharge section area, $R$ is the hydraulic radius, $n$ is the roughness coefficient and $I$ is the water surface slope.

After canalization, natural river course of Zhongjian River district section has been transformed into nearly parallel and regular on both sides, and the trend of the river remain unchanged before and after the river canalization, so the water surface slope I could be considered to change little before and after the river canalization. Under the same water level, river bed base was raised $0.5 \mathrm{~m}$ at most, which showed marked difference campared with the at least $5 \mathrm{~m}$ flood depths, so the hydraulic radius $\mathrm{R}$ can be considered to be a constant. After the flood level rising to $495.0 \mathrm{~m}$, discharge section area was relatively reduced by $25 \%$ to $28 \%$ from the data. And when the flood level was rised to a certain position (the width and depth ratio $B / h$ was greater than 50), the roughness coefficient $n$ was relatively reduced by $20 \%$. So Relative reduction of the numerator was greater than the denominator in Formula 2, and the conclusion that the river flood discharge was reduced after channelizing reconstruction can be inferred, which was consistent with the results obtained by the hydrological alteration diagnosis system. A fainal conclusion that flood variation was exacerbated by channelizing reconstruction to some extent.

Environmental change contains climate change and human activity, and the response of its hydrological elements that can be attributed to rainfall change and runoff change; rainfall mainly reflects the response of climate change, and runoff mainly reflects the response of human activity. A moderate variation occurred for the runoff in Xuanen according to the alteration diagnosis of the annual maximum daily flow series, which indicated 
that this area was controlled by the human activities. In addition, the runoff series jumped a downward in 1999; the Longdong reservoir in this area was completed in 1995, which played a role in flood cotrolling for natural floods, but its completed time was later than the rainfall series variation time and the runoff series variation time, which indicated that climate change could be primed for the runoff variation, water conservancy project came second. Meanwhile, river canalization has started in 2005, exacerbating impact of human activities, which made amade a new demand for revising the plan of floodearlying warning.

\section{CONCLUSION}

With the data of annual maximum daily flow series from 1962-2013, the Hydrological Alteration Diagnosis System was used to estimate the consistency of the series. The main conclusions in this paper are as follows: Firstly, the annual maximum daily flow series from 1962-2013 jumped a downward moderate variation in 1999, which indicated that the dual influence of human activities leaded to the variation of the annual maximum daily flow. Secondly, river canalization has started in 2005 and completed in 2012, which has reduced the flood discharge at equal water level, aggravating the flood variation to a certain extent. Finaly, human activities have great influence on the flood control abilities of urban water bodies of Xuanen. So the flood warning plan needs to adapt to the changing environment, which makes river flood prevention decision more scientific and feasible.

\section{ACKNOWLEDGMENT}

This work is supported by the National Nature Science Foundation of China (Grant No.51190094, Grant No.50979075 and Grant No.51179131), the special research project of Hubei province water conservancy (HBSLKJZX201301) and Guangdong province water conservancy science and technology innovations (2011-01).

\section{REFERENCES}

[1] Xu B., Xie P., Tang Y. Y., et al, "Analysis of flood returning to main channel influence on the flood control ability of Xijiang River," Journal of Hydroelectric Engineering, vol. 33, pp. 65-72, 2014.

[2] Chebana, F., et al., "Testing for multivariate trends in hydrologic frequency analysis," Journal of Hydrology , vol. 488, pp. 519-530, 2013

[3] Zhang Q., Gu X. H., Vijay P. S., Xiao M. Z., "Flood frequency analysis with consideration of hydrological alterations: Changing properties, causes and implications," Journal of Hydrology, vol. 519, Part A, pp. 803-813, 2014.

[4] Sang Y. F., Wang Z. G., Liu C. M., "Comparison of the MK test and EMD method for trend identification in hydrological time series," Journal of Hydrology, vol. 510, pp. 293-298, 2014.

[5] Jiang, L. Z., et al., "Assessment of Hydrologic Alterations Caused by the Three Gorges Dam in the Middle and Lower Reaches of Yangtze River, China," Water, vol. 6, pp.1419-1434, 2014

[6] Xu, G. L., et al., "Temporal and spatial variation of water level in urbanizing plain river network region." Water Science and Technology, vol. 69, pp. 2191-2199, 2014.

[7] Du, H., et al., "Variations and statistical probability characteristic analysis of extreme precipitation events under climate change in Haihe River Basin, China," Hydrological Processes, vol. 28, pp. 913-925, 2014.

[8] Worrall, T. P., et al., "The identification of hydrological indices for the characterization of macroinvertebrate community response to flow regime variability," Hydrological Sciences Journal-Journal Des Sciences Hydrologiques vol. 59, pp. 645-658, 2014.

[9] Machiwal, D., Jha, M.K., Hydrologic Time Series Analysis: Theory and Practice. Berlin: Springer-Verlag, 2012

[10] Jayawardena, A.W. and Lau, W.H. "Homogeneity tests for rainfall data," Journal of the Hong Kong Institution of Engineers, September 1990, pp 22-25.

[11] Xie P., Chen G. C., Lei H. F., et al. Surface water resources evaluation methods on changing environment. Beijing: science press, 2009.

[12] Hurst H E, Black R P, Simaika Y M. Long-term Storage:An Experimental Study, London: Constable, 1965.

[13] Mandelbrot B B, Wallis J R. "Computer experiments with fractional Gaussian noises, (Part 1 and Part 2)" Water Resources Research, vol. 5, pp. 228-259, 1969.

[14] Li H. Q., Wang F. Q., Fractional theory and its Applications in molecular Science, Science Press, Beijing, 1993: 41-59. 